\title{
Latent Light Binding Energy: \\ Its Relevance to Lasers and White Light
}

\author{
Madhav G. Deo \\ Honorary Scientist, \\ Indian National Science Academy, New Delhi, India \\ Moving Academy of Medicine and Biomedicine, \\ 2nd Floor, 'Rainbow', \\ Baner Road, Pune 411045 (India)
}

Email: deo.madhav@gmail.com

Tel: Cell (Mobile) +919922403266

Land line +91-20-2729 5354

(This is a single author MS) 


\begin{abstract}
Physics behind collimated highly directional nature of lasers, and factors that keep the seven coloured waves that form white light together during their journey from Sun to Earth, in the face of the natural disruptive forces, is not fully understood. Energy levels were measured, in terms of alterations in induced current and voltage, in beams from a red laser, white LED light and the Sunlight before and during their disruption by diffusers (frosted glass for the lasers) and diffractors (diffraction grating for the white light) using a photovoltaic solar cell panel attached to a digital multimeter. Results show that disruption of the beams results in release of extra energy named as 'Latent Light Binding' Energy'. It is hypothesized that the 'binding' energy keeps laser waves firmly bound together both end-on and side-on enabling laser beams to travel long distances in collimated manner. Likewise, the 7 coloured waves that constitute white light are kept together, probably side-on, in their journey from the Sun to the Earth. The observation that diffraction of sunbeam is associated with increased power generation provides a new lead to improve harnessing of solar energy, where, currently, the focus is mainly on improving efficiency of photovoltaic cell.
\end{abstract}

Key words

Binding energy in lasers; Latent Binding energy in white light; Harnessing binding energy in sunlight 


\section{Introduction:}

Amongst various sources of light, 'Laser' is unique in the sense that it is monochromatic, coherent and highly directional. Most of the properties of the laser are attributed to the basic underlying physics that is summed up in the word LASER itself - Light Amplification by the Stimulated Emission of Radiation [1]. However, physics behind the collimated and highly directional nature, over very long distances, remains ill understood. Sun light has been travelling to the Earth since the it was created estimated 4.5 billion of years ago. Yet, it was only 350 years ago that Newton's classical prism experiments showed that white sunlight is made of 7 colours. What keeps the coloured waves together defying natural disruptive electro-magnetic forces during their very long journey of millions of miles from the Sun to the Earth is not fully known? One possibility, which can explain both the phenomena, is that the adjoining waves are firmly kept together by a 'binding' force (energy). The data of this study, in which the energy levels are measured in terms of current and voltage generated by a photovoltaic solar panel exposed to laser and white light beams before and after their disruption by diffusers/diffractors, support this notion.

\section{Results:}

\section{Laser studies:}

Beams from each of the three lasers (Red, Green and Blue) were disrupted by passing them individually through a diffuser/diffractor. Only the results of the red laser beam are described in details. Other two lasers showed a similar pattern but of different magnitude (Table 1).

Table I: Voltage and current induced by different lasers before and after diffusion and diffraction of their beams

\begin{tabular}{|c|l|c|c|c|c|c|c|}
\hline \multirow{2}{*}{ Parameter } & & \multicolumn{2}{|c|}{ Red } & \multicolumn{2}{c|}{ Green } & \multicolumn{2}{c|}{ Blue } \\
\cline { 2 - 8 } & & $\begin{array}{c}\text { Abs } \\
\text { values }\end{array}$ & $\begin{array}{c}\text { \% } \\
\text { change }\end{array}$ & $\begin{array}{c}\text { Abs } \\
\text { values }\end{array}$ & $\begin{array}{c}\text { \% } \\
\text { change }\end{array}$ & $\begin{array}{c}\text { Abs } \\
\text { values }\end{array}$ & $\begin{array}{c}\text { \% } \\
\text { change }\end{array}$ \\
\hline \multirow{2}{*}{$\begin{array}{c}\text { Current } \\
(\mu \mathrm{A})\end{array}$} & Basal & $2.78 \pm 0.22$ & & $7.75 \pm 1.23$ & & $3.92 \pm 0.35$ & \\
\cline { 2 - 8 } & Diffusion & $5.96 \pm 0.08$ & 114 & $12.27 \pm 0.63$ & 58 & $8.16 \pm 0.95$ & 108 \\
\cline { 2 - 8 } & Diffraction & $5.37 \pm 0.11$ & 93 & $11.52 \pm 0.43$ & 49 & $6.47 \pm 0.69$ & 65 \\
\hline \multirow{2}{*}{$\begin{array}{c}\text { Volts } \\
(\mathrm{V})\end{array}$} & Basal & $1.05 \pm 0.11$ & & $1.73 \pm 0.13$ & & $1.34 \pm 0.10$ & \\
\cline { 2 - 8 } & Diffusion & $1.74 \pm 0.02$ & 66 & $2.20 \pm 0.08$ & 27 & $1.93 \pm 0.07$ & 44 \\
\cline { 2 - 8 } & Diffraction & $1.62 \pm 0.02$ & 54 & $2.14 \pm 0.07$ & 24 & $1.82 \pm 0.08$ & 36 \\
\hline \multirow{2}{*}{$\begin{array}{c}\text { Wattage } \\
(\mu \mathrm{W})\end{array}$} & Basal & $2.91 \pm 0.52$ & & $13.51 \pm 3.11$ & & $5.27 \pm 0.81$ & \\
\cline { 2 - 8 } & Diffusion & $10.38 \pm 0.19$ & 257 & $26.98 \pm 2.23$ & 100 & $15.76 \pm 2.41$ & 199 \\
\cline { 2 - 8 } & Diffraction & $8.7 \pm 0.29$ & 99 & $24.65 \pm 1.68$ & 82 & $11.82 \pm 1.62$ & 124 \\
\hline
\end{tabular}

Results are shown as mean \pm SD of 6 paired observations.

Differences between basal and diffusion/diffraction in all parameters and for each coloured laser were very highly significant statistically $(\mathrm{p}<0.001)$ 
The mean basal energy level of the directly focused red laser beam was $2.78 \pm 0.22 \mu \mathrm{A}$.. Scattering (Diffusion) and diffraction raised the level to $5.96 \pm 0.08 \mu \mathrm{A}$ and $5.37 \pm 0.11 \mu \mathrm{uA}$ respectively (Table 1). In terms of percentage, the corresponding increase was $114 \%$ and $93 \%$. Enhancement of lower order was also recorded in the voltage; being $66 \%$ and $54 \%$ after diffusion and diffraction respectively. Maximum change was seen in the generated power (wattage). Its mean levels were $2.91 \pm 0.52 \mu \mathrm{W}, 10.39 \pm 0.19 \mu \mathrm{W}$ and $8.7 \pm 0.29 \mu \mathrm{W}$ for un-diffracted, diffused and diffracted beams respectively.

Experiments with four lasers: Because of its nature, the laser beam gets very sharply focused and therefore may stimulate only a small group of solar cells, leaving substantial area of the solar panel unstimulated. The increase in 'energy' level observed in these studies could be due to (a) the exposure of the unstimulated area of the panel and/or (b) increased flux of photons. To overcome the problem, four red lasers were simultaneously beamed each on one quadrant of panel that resulted in stimulation of all PV cells in each row of the panel (Fig 1). A frosted glass diffuser was used to scatter all beams simultaneously. Induced current and voltage were recorded before and after the beams were scattered
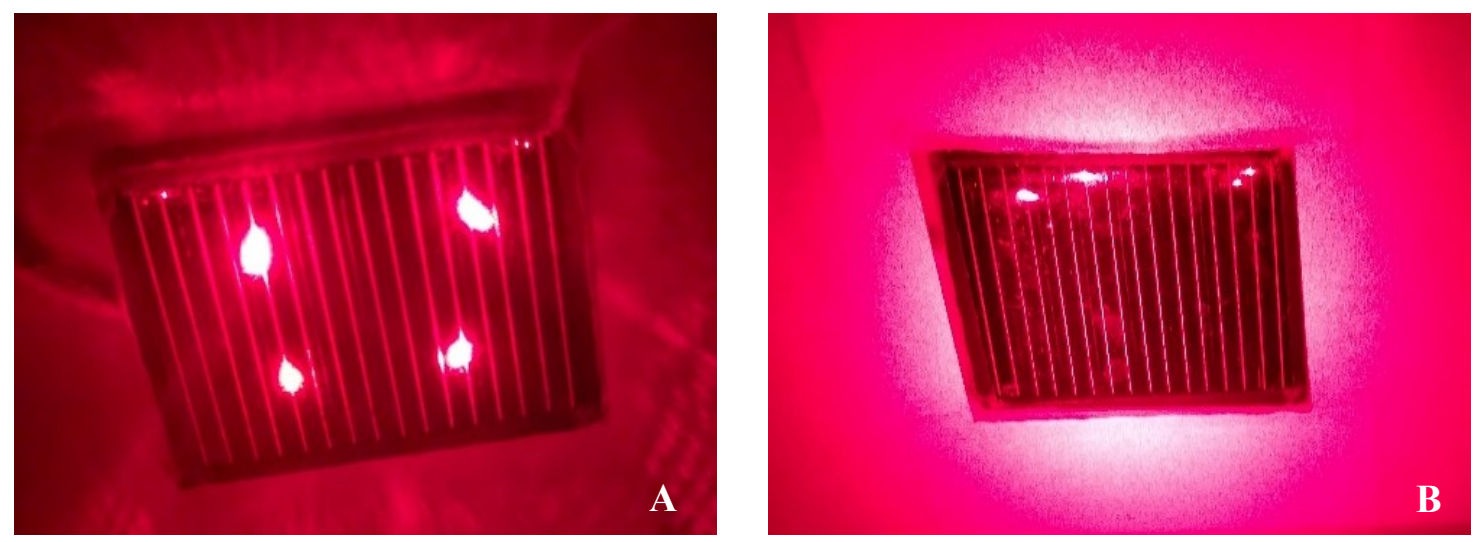

Fig 1: Four lasers before (A) and after diffusion of their beams. (A) All rows of the PV cells are stimulated and borders show red hue indication that the entire panel is stimulated. (B) Picture after diffusion of the lasers beams. Portions of the scattered beams can be seen bordering the panel and the red glow surrounding the panel has visually increased.

The mean current level before and after diffusion was $0.023 \pm 0.003 \mathrm{~mA}$ and $0.22 \pm 0.042 \mathrm{~mA}$ respectively (Table II. Thus, scattering results in $857 \%$ increase in the current. Similar enhancement was observed in the wattage. However, the voltage showed only marginal increase $(20 \%)$. 
Table II: Current and voltage induced by simultaneously activated four red lasers before and after diffusion and diffraction of their beams

\begin{tabular}{|c|c|c|c|c|c|c|c|c|c|}
\hline & \multicolumn{2}{|c|}{ Current (mA) } & \multirow[t]{2}{*}{$\%$} & \multicolumn{2}{|c|}{ Voltage (V) } & \multirow[t]{2}{*}{$\%$} & \multicolumn{2}{|c|}{ Wattage (mW) } & \multirow[t]{2}{*}{$\%$} \\
\hline & Direct & Diffusion & & Direct & Diffusion & & Direct & Diffusion & \\
\hline 1 & 0.020 & 0.170 & 750 & 2.44 & 3.36 & 38 & 0.049 & 0.571 & 1065 \\
\hline 2 & 0.018 & 0.172 & 856 & 2.72 & 3.32 & 22 & 0.049 & 0.571 & 1065 \\
\hline 3 & 0.027 & 0.256 & 848 & 2.93 & 3.30 & 13 & 0.079 & 0.845 & 970 \\
\hline 4 & 0.023 & 0.242 & 952 & 2.78 & 3.35 & 21 & 0.064 & 0.811 & 1167 \\
\hline 5 & 0.022 & 0.213 & 868 & 2.70 & 3.21 & 19 & 0.059 & 0.684 & 1059 \\
\hline 6 & 0.025 & 0.266 & 964 & 2.90 & 3.27 & 13 & 0.073 & 0.870 & 1092 \\
\hline Mean & 0.023 & 0.220 & 857 & 2.75 & 3.30 & 20 & 0.062 & 0.725 & 1069 \\
\hline $\mathrm{SD} \pm$ & 0.003 & 0.042 & & 0.176 & 0.056 & & 0.012 & 0.135 & \\
\hline $\mathrm{P}<$ & \multicolumn{2}{|c|}{0.001} & & \multicolumn{2}{|c|}{0.001} & & \multicolumn{2}{|c|}{0.001} & \\
\hline
\end{tabular}

Results are shown as mean \pm SD of 6 paired observations.

Differences between basal and diffusion/diffraction in all parameters laser were very highly significant statistically

Alterations in optical properties: Changes in the optical properties characteristic of the laser such as its monochromatic nature, sharpness of the focused beam ('focusibility') and response to linear polarizer were studied before and after scattering. The red laser beam focused on a diffraction grating (600L/mm; HSG15K, Hilger Analytical, England) yielded a central un-diffracted spot $(\mathrm{m}=0)$ flanked by a number of spots of reduced intensities on either side of which only the first diffraction order $(\mathrm{m}=1)$ is considered. The spots were very bright and sharp (Fig. 2). After scattering, the beam was focused on the grating using a convex lens of focal length $5 \mathrm{~cm}$. Although the diffraction pattern was qualitatively the same, an indication that it had retained monochromatism of the parent beam, but the focused spots never reached the brightness/sharpness of the parent laser beam indicating reduced 'focusibility' of the scattered laser beam
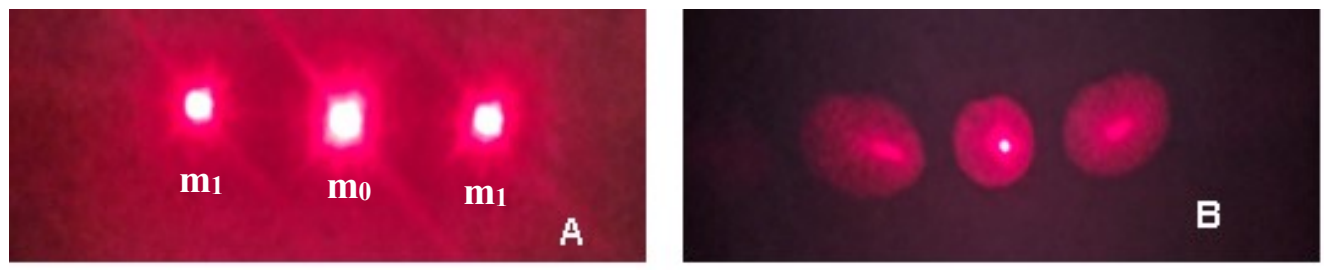

Fig 2. Behavior of the laser beams before and after scattering. (A) Direct and (B) Scattered (diffused) laser beams focused on the grating with convex lens $(f=5 \mathrm{~cm})$. The latter has lost both brightness and sharpness as it could not be sharply focused. 
Linear polarization properties of the red laser beam were studied by focusing it through a polarizer on to a white screen before and after scattering. The polarizer was rotated till the brightest image of the beam was obtained (Fig.3). Turning the polarizer through $90^{\circ}$ resulted in producing the dimmest beam, an indication that the laser used in this study was polarized in one plane only. Although scattered laser beam physically looked more like ordinary light that gets partially polarized in both planes, the former (laser) could be polarized in one plane only. Positions of the polarizer for producing the brightest and dimmest beams were identical for the laser and the scattered beam, indicating that the latter had retained the properties of the parent beam. The scattered beam thus retains the two of the three important properties of the parent laser. It remained monochromatic and coherent in the same phase as the parent beam. However, it lacked the 'highly directional' nature of the parent beam.
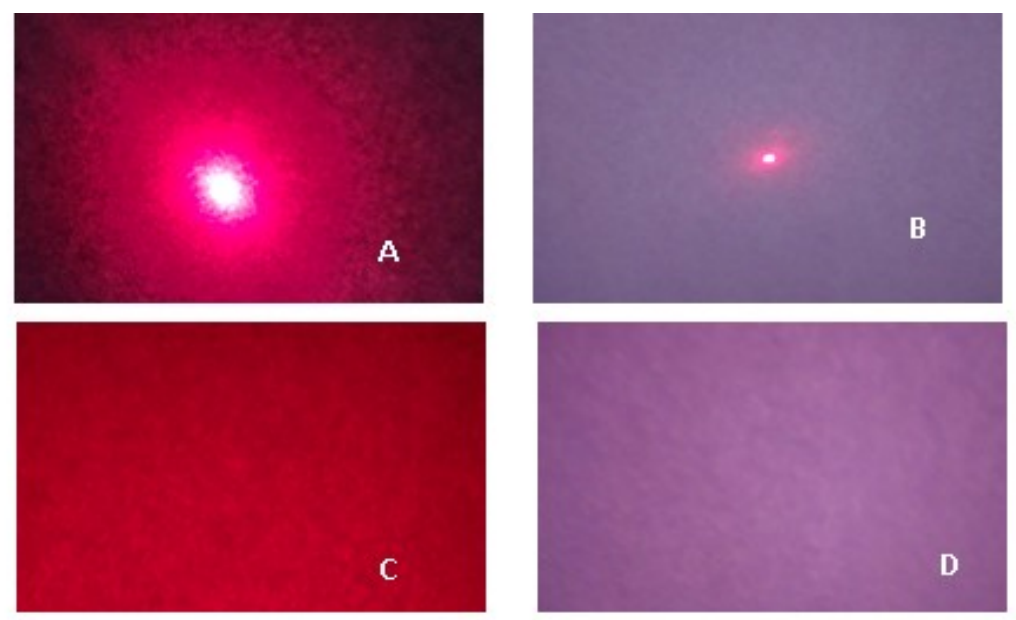

Fig 3: Photographs of laser beam passed through a linear polarizer (A) in phase with the laser and (B) when the polarizer was turned through $90^{\circ}$. Brightest image was produced when the polarizer was in phase (A) and dimmest (B)when it was turned through $90^{\circ}$. Figures $\mathrm{C}$ and $\mathrm{D}$ are the photographs of the laser after it was passed through a diffuser. Positions of the polarizers at $\mathrm{C}$ and $\mathrm{D}$ were the same as were for $\mathrm{A}$ and $\mathrm{B}$ respectively. Thus, the brightest and dimmest images were generated at $\mathrm{A} \& \mathrm{C}$ and $\mathrm{B} \& \mathrm{D}$ respectively.

\section{White flashlight:}

Effects of 3 input currents (1.45A, 0.1A and 0.04A) on the energy levels in beams from three zones of LED white flashlight before and after diffraction through the grating were investigated (Fig 4). At the input current of $1.45 \mathrm{~A}$, the mean currents induced by direct (un-diffracted) beams from the inner, middle and outer zones were $6.33 \pm 0.52 \mathrm{~mA}, 4.05 \pm 0.11 \mathrm{~mA}$ and $1.99 \pm \mathrm{mA}$ respectively. The corresponding values for the same beams after diffraction were $32.5 \pm 1.64 \mathrm{~mA}, 7.08 \pm 0.38 \mathrm{~mA}$ and $2.09 \pm 0.38 \mathrm{~mA}$ (Table III) representing increase of $413 \% ; 75 \%$ and $5 \%$ respectively. Similar alterations were recorded in induced voltage but at a much lower level. 
Table III: Response of solar panel to direct and diffracted beams from different zones of white flashlight

\begin{tabular}{|c|c|c|c|c|c|c|c|c|c|}
\hline \multirow{3}{*}{ Zones } & \multicolumn{3}{|c|}{ Input current $1.45 \mathrm{~A}$} & \multicolumn{3}{|c|}{ Input current $0.1 \mathrm{~A}$} & \multicolumn{3}{|c|}{ Input current $0.04 \mathrm{~A}$} \\
\hline & Direct & Diffracted & $\begin{array}{c}\% \\
\text { Increase }\end{array}$ & Direct & Diffracted & $\begin{array}{c}\% \\
\text { Increase }\end{array}$ & Direct & Diffracted & $\begin{array}{c}\% \\
\text { Increase }\end{array}$ \\
\hline & \multicolumn{9}{|c|}{ Current $(\mu \mathrm{A})$} \\
\hline Innermost & $6.33 \pm 0.52$ & $32.50 \pm 1.64 * * *$ & 413 & $4.20 \pm 0.05$ & $12.89 \pm 0.12 * * *$ & 207 & $3.30 \pm 0.01$ & $8.23 \pm 0.48 * * *$ & 149 \\
\hline Middle & $4.05 \pm 0.11$ & $7.08 \pm 0.38 * * *$ & 75 & $2.54 \pm 0.03$ & $4.36 \pm 0.09 * * *$ & 72 & $1.71 \pm 0.02$ & $2.57 \pm 0.10 * * *$ & 50 \\
\hline \multirow[t]{2}{*}{ Outermost } & $1.99 \pm 0.03$ & $2.09 \pm 0.38 * *$ & 5 & $0.95 \pm 0.01$ & $1.06 \pm 0.10 * * *$ & 12 & $0.60 \pm 0.05$ & $0.65 \pm 0.01 * *$ & 8 \\
\hline & \multicolumn{9}{|c|}{ Voltage (V) } \\
\hline Innermost & $0.83 \pm 0.02$ & $1.68 \pm 0.04 * * *$ & 102 & $0.55 \pm 0.01$ & $1.06 \pm 0.01 * * *$ & 93 & $0.44 \pm 0.02$ & $0.80 \pm 0.01 * * *$ & 82 \\
\hline Middle & $0.46 \pm 0.01$ & $0.64 \pm 0.03 * * *$ & 39 & $0.31 \pm 0.01$ & $0.45 \pm 0.01 * * *$ & 45 & $0.21 \pm 0.01$ & $0.29 \pm 0.01 * * *$ & 38 \\
\hline \multirow[t]{2}{*}{ Outermost } & $0.20 \pm 0.01$ & $0.22 \pm 0.01 * * *$ & 10 & $0.11 \pm 0.01$ & $0.12 \pm 0.01 * *$ & 9 & $0.07 \pm 0.01$ & $0.07 \pm 0.01 * * *$ & 9 \\
\hline & \multicolumn{9}{|c|}{ Power $(\mu W)$} \\
\hline Innermost & $5.27 \pm 0.49$ & $54.6 \pm 3.58$ & 936 & $2.31 \pm 0.05$ & $13.71^{`} \pm 0.02$ & 494 & $1.44 \pm 0.11$ & $6.61 \pm 0.45$ & 359 \\
\hline Middle & $1.87 \pm 0.01$ & $4.54 \pm 0.04$ & 143 & $0.79 \pm 0.02$ & $1.96 \pm 0.07$ & 148 & $0.36 \pm 0.01$ & $0.74 \pm 0.04$ & 106 \\
\hline Outermost & $0.39 \pm 0.01$ & $0.46 \pm 0.04$ & 18 & $0.11 \pm 0.01$ & $0.13 \pm 0.02$ & 28 & $0.04 \pm 0.01$ & $0.05 \pm 0.01$ & 18 \\
\hline
\end{tabular}

Results expressed as mean \pm SD of 6 paired observations. Students paired $t$ test was applied

** Statistically high significant $(\mathrm{P}<0.01)$; ** Statistically very highly significant $(\mathrm{P}<0.001)$

To test the applicability of these observations to the overall issue of solar energy, studies were conducted first in sunshade and later in broad daylight using a specially fabricated aluminium rack (Fig.4). The solar panel (16 cm x $8 \mathrm{~cm}$; rating of $6 \mathrm{~V}$ and $300 \mathrm{~mA}$ ) was exposed simultaneously to 4 LED white flashlights in a sunshade using the rack. The flashlights were fixed on a cardboard of suitable size carrying 4 windows, each of $2.8 \mathrm{~cm}$ diameter, to accommodate the flashlights. The windows were placed such that each flashlight illuminated one quadrant, thus illuminating the entire solar panel (Fig 6). After recording the basal values, 4 diffraction gratings (one per flashlight) were interposed between the flashlight and the solar panel. The mean combined current and voltage induced by the flashlights were $3.32 \pm 0.12 \mathrm{~mA}$ and $3.79 \pm 0.13 \mathrm{~V}$ respectively (Table IV). When the light beams were passed through the diffraction grating the readings went up to $6.28 \pm 0.19 \mathrm{~mA}$ and $4.72 \pm 0.14 \mathrm{~V}$ respectively, corresponding to increase of $90 \%$ and $13 \%$ over their basal levels (Table IV). Voltage showed similar alterations but at a much lower level. The mean combined basal power generated by the flashlights was $12.58 \mathrm{~mW}$. Diffraction resulted in raising it to $26.81 \mathrm{~mW}$, an increase of $113 \%$. 
Table IV: Response of solar panel to LED white flashlight before and after diffraction.

\begin{tabular}{|c|c|c|c|c|c|c|c|c|c|}
\hline \multirow[b]{2}{*}{ SN } & \multicolumn{3}{|c|}{ Current (mA) } & \multicolumn{3}{|c|}{ Volts (V) } & \multicolumn{3}{|c|}{ Watt (mW) } \\
\hline & Direct & Grating & $\begin{array}{c}\% \\
\text { Change } \\
*\end{array}$ & Direct & Grating & $\begin{array}{c}\% \\
\text { Change* }\end{array}$ & Direct & Grating & $\begin{array}{c}\% \\
\text { Change* }^{*}\end{array}$ \\
\hline 1 & 3.30 & 6.50 & 97 & 3.96 & 4.16 & 05 & 13.07 & 27.04 & 107 \\
\hline 2 & 3.30 & 6.50 & 97 & 3.69 & 4.41 & 20 & 12.18 & 28.67 & 135 \\
\hline 3 & 3.50 & 6.00 & 71 & 3.63 & 4.39 & 21 & 12.71 & 26.34 & 107 \\
\hline 4 & 3.20 & 6.20 & 94 & 3.93 & 4.12 & 05 & 12.58 & 25.54 & 103 \\
\hline 5 & 3.20 & 6.30 & 97 & 3.75 & 4.40 & 17 & 12.00 & 27.72 & 131 \\
\hline 6 & 3.40 & 6.20 & 82 & 3.80 & 4.12 & 08 & 12.92 & 25.54 & 98 \\
\hline Mean & 3.32 & 6.28 & 89 & 3.79 & 4.27 & 13 & 12.58 & 26.81 & 113 \\
\hline $\mathrm{SD} \pm$ & 0.12 & 0.19 & & 0.13 & 0.14 & & 0.48 & 1.24 & \\
\hline $\mathrm{P}<$ & \multicolumn{2}{|c|}{0.001} & & \multicolumn{2}{|c|}{0.007} & & \multicolumn{2}{|c|}{0.001} & \\
\hline
\end{tabular}

Students paired $t$ test was applied

* Denote percentage increase over the corresponding values observed in 'Direct beam'

\section{Experiments with Sunlight:}

Experimental set up for the study in shown in (Fig 6) The mean current induced by direct, focused and diffracted beams was $20.1 \pm 0.27 \mathrm{~mA}, 31.4 \pm 1.56 \mathrm{~mA}$ and $42.3 \pm 7.00 \mathrm{~mA}$ respectively. Thus, focused beam raised the current by $56 \%$ over its basal value. Diffraction of the beam raised it further to $110 \%$. However, the picture was different when the energy levels were measured in terms of voltage. The mean voltage induced by the direct beam was $4.53 \pm 0.02 \mathrm{~V}$. The focused beam raised it to $5.11 \pm 0.02 \mathrm{~V}$, an increase of just $13 \%$. Diffraction did not induce any further change in the voltage. The mean power (V x A) generated by direct, focused and diffracted beams, was $91.1 \pm 1.59 \mathrm{~mW}$, $160.4 \pm 8.49 \mathrm{~mW}$ and $216.1 \pm 36.27 \mathrm{~mW}$ respectively (Table V).

Table V: Power generated by direct, focused and diffracted sunlight beams

\begin{tabular}{|c|l|c|c|c|c|c|}
\hline & & Direct & Focused & $\begin{array}{c}\text { \% } \\
\text { Change* }\end{array}$ & Diffracted & $\begin{array}{c}\% \\
\text { Change* }\end{array}$ \\
\hline $\mathbf{1}$ & Rotation (RPM) & $5129 \pm 61.09$ & $7065 \pm 19.3$ & 38 & $10778 \pm 770.5$ & 110 \\
\hline $\mathbf{2}$ & Wattage (mW) & $91.1 \pm 1.59$ & $160.4 \pm 8.49$ & 76 & $216.1 \pm 36.27$ & 137 \\
\hline $\mathbf{3}$ & Current (mA) & $20.1 \pm 0.27$ & $31.4 \pm 1.57$ & 56 & $42.3 \pm 1.57$ & 110 \\
\hline $\mathbf{4}$ & Voltage (V) & $4.53 \pm 0.02$ & $5.11 \pm 0.03$ & 13 & $5.11 \pm 0.02$ & 13 \\
\hline
\end{tabular}

Results are expressed as means \pm SD of 6 paired observations

$\mathrm{P}$ is very highly significant $(\mathrm{P}<0.001)$ in all parameters for

(a) Direct vs Focused; (b) Direct vs Diffracted and (c) Focused vs Diffracted

* Denote percentage increase over the corresponding values observed in the 'Direct' beam' 
To study functionality of these observations, a toy fan of $50 \mathrm{~mW}$ was placed in series with the multimeter. The rotational speed (rotation per minute; RPM) of the fan showed progressive increase commensurate with increase in the generated power (table V). The mean RPM induced by the direct beam was $5129 \pm 61.09$ RPM. The focused and diffracted beams increased the RPM to $7065 \pm 139.3$ RPM (38\%) and 10778 \pm 770.5 RPM (110\%) respectively (see the Video titled "Latent Binding Energy").

\section{Testing the hypothesis of the 'binding' energy:}

As discussed later, the maximum response capacity of the solar panel could have bearing on the hypothesis. To get an idea of its response capability, the panel was exposed to bright sunlight around 10.00 am on a weekday in March 2018 in Pune (India) when the average daily maximum temperature of the city is $36^{\circ} \mathrm{C}$ for the month. This resulted in generation of $2.47 \mathrm{~mA}$ current and $14.12 \mathrm{~mW}$ power per sq. $\mathrm{cm}$ of the panel (Table VI). The corresponding figures for the flashlight beam were $1.31 \mu \mathrm{A}$ and $2.07 \mu \mathrm{W}$. Thus, the current and power generated by the flashlight in comparison to sunlight was only $0.05 \%$ and $0.008 \%$ respectively, an indication that the response capacity of the panel was not saturated upon exposure to direct flashlight beam.

Table VI. Response of solar panel to bright sunlight (maximum response) and the flashlight

\begin{tabular}{|c|c|c|c|c|c|c|c|c|c|c|}
\hline & Area & \multicolumn{2}{|c|}{ Current } & & \multicolumn{2}{|c|}{ Voltage } & & \multicolumn{2}{|c|}{ Wattage } & \multirow[b]{2}{*}{$\begin{array}{l}\% \text { age of } \\
\text { the } \\
\text { maximum }\end{array}$} \\
\hline & & $\begin{array}{c}\text { Total } \\
\text { response }\end{array}$ & $\begin{array}{l}\text { per } \\
\text { sq. } \\
\text { cm }\end{array}$ & $\begin{array}{l}\% \text { age of } \\
\text { the } \\
\text { maximum }\end{array}$ & $\begin{array}{c}\text { Total } \\
\text { response }\end{array}$ & $\begin{array}{c}\text { per } \\
\text { sq } \\
\text { cm }\end{array}$ & $\begin{array}{l}\% \text { age of } \\
\text { the } \\
\text { maximum }\end{array}$ & $\begin{array}{c}\text { Total } \\
\text { response }\end{array}$ & $\begin{array}{c}\text { per sq } \\
\text { cm }\end{array}$ & \\
\hline $\begin{array}{l}\begin{array}{l}\text { Sunlight } \\
\text { (maximum) }\end{array} \\
\end{array}$ & 112 & $\begin{array}{c}277 \pm 4.0 \\
(\mathrm{~mA})\end{array}$ & $\begin{array}{c}2.47 \\
(\mathrm{~mA})\end{array}$ & & $5.7 \pm 0.01$ & 0.05 & & $\begin{array}{c}1581 \pm 25.53 \\
(\mathrm{~mW})\end{array}$ & $\begin{array}{l}14.12 \\
(\mathrm{~mW})\end{array}$ & \\
\hline Flashlight & 12.56 & $\begin{array}{c}16.5 \pm 2.59 \\
(\mu \mathrm{A})\end{array}$ & $\begin{array}{l}1.31 \\
(\mu \mathrm{A})\end{array}$ & 0.05 & $0.81 \pm 0.1$ & 0.06 & 20 & $\begin{array}{c}13.4 \pm 3.75 \\
(\mu W)\end{array}$ & $\begin{array}{c}1.07 \\
(\mu W)\end{array}$ & 0.008 \\
\hline
\end{tabular}

Absolute values expressed as mean \pm SD of 6 observations

In another study, a beam from the inner most (brightest) zone of the flashlight was passed through a black screen with an aperture of $1.00 \mathrm{~cm}$ diam. The distance between the flashlight and the solar panel was $30 \mathrm{~cm}$. The screen was kept at a distance $(16 \mathrm{~cm})$ so as to produce a beam of $36 \mathrm{~mm}$ diameter would cover the entire solar panel leaving no unexposed unstimulated area (Fig.8). Beam was then diffracted using the diffraction grating.

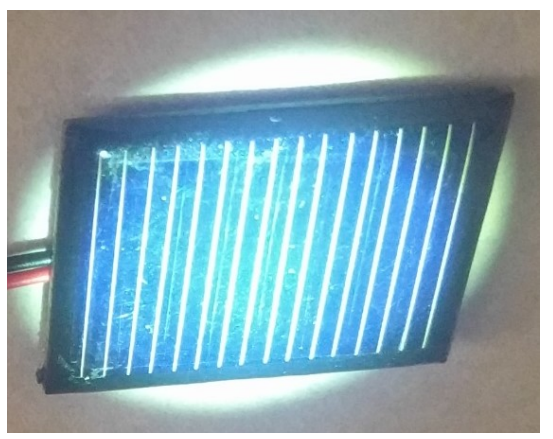

Fig 8 Totally illuminated solar panel with direct beam from brightest zone of the flashlight 
The mean current induced by direct and diffracted beam was $0.021 \pm 0.01 \mathrm{~mA}$ and $0.041 \pm 0.01 \mathrm{~mA}$. Thus, even without availability of unexposed unstimulated PV cells there was an increase of 95\% in the induced current (Table VII). However, there was hardly any change in the induced voltage.

Table VII: Current and Voltage induced by flashlight beam before and after diffraction.

\begin{tabular}{|c|c|c|c|c|c|c|c|c|c|}
\hline & \multicolumn{3}{|c|}{ Current (mA) } & \multicolumn{3}{|c|}{ Voltage (V) } & \multicolumn{3}{|c|}{ Wattage (mW) } \\
\hline & Direct & Diffracted & $\% *$ & Direct & Diffracted & $\% *$ & \begin{tabular}{|l|} 
Direct \\
\end{tabular} & Diffracted & $\%$ * \\
\hline 1 & 0.020 & 0.039 & 95 & 2.31 & 2.22 & -4 & \begin{tabular}{|l|l|}
0.046 \\
\end{tabular} & 0.087 & 89 \\
\hline 2 & 0.019 & 0.038 & 100 & 2.42 & 2.27 & -6 & 0.046 & 0.086 & 87 \\
\hline 3 & 0.022 & 0.048 & 118 & 2.56 & 2.40 & -6 & 0.056 & 0.115 & 105 \\
\hline 4 & 0.020 & 0.035 & 75 & 2.39 & 2.17 & -9 & \begin{tabular}{|l|l|}
0.048 \\
\end{tabular} & 0.076 & 58 \\
\hline 5 & 0.023 & 0.041 & 78 & 2.51 & 2.26 & -10 & \begin{tabular}{|l|}
0.058 \\
\end{tabular} & 0.093 & 60 \\
\hline 6 & 0.024 & 0.042 & 75 & 2.52 & 2.34 & -7 & 0.060 & 0.098 & 63 \\
\hline Mean & 0.021 & 0.041 & 95 & 2.45 & 2.28 & -7 & 0.052 & 0.092 & 77 \\
\hline $\mathrm{SD} \pm$ & 0.001 & 0.004 & & 0.094 & 0.083 & & 0.006 & 0.013 & \\
\hline $\mathrm{P}<$ & & 0.001 & & & 0.001 & & & 0.001 & \\
\hline
\end{tabular}

\section{Discussion:}

Results of these studies indicate that disruption of lasers by diffusion (scattering) by frosted glass or diffraction by a perforated surgical tape results in release of extra energy. Although the scattered laser beam looks physically like a beam of ordinary diffuse light, it continues to be monochromatic and coherent in the phase identical to the parent beam. Yet, the disrupted beam cannot be reconverted into a laser. Also, when a beam of white light, both from a flashlight or sunlight, is passed through a diffraction grating it is split into its 7 component colours, simultaneously, releasing extra energy. The released energy is named by the author as the 'latent light binding energy', referred to as the 'binding' energy in the subsequent discussions [2]

According to the law of conservation of energy, total energy in the direct and diffracted white light beams should be the same. However, this is not the case in the present study as the diffracted beam shows higher energy levels. One way to look at it is that the intensity of the directly focused beams is so high that the exposed area of the panel gets saturated resulting in under recording of the beam energy. Increased energy levels observed in the diffracted beam are simply due to lateral spreading of the beam exposing larger unstimulated area of the panel. In other words, the true energy levels are those in the diffracted beams and the lower levels observed in the direct beam are simply due to under reporting. Such interpretation will also satisfy the conservation law. However, saturation and 
therefore under reporting will only occur if the energy in the direct beam exceeds the response capacity of the PV cells in the solar panel. This does not appear to be the case, as the power (wattage) generated by the un-diffracted beam is only $0.008 \%$ of the maximum response capacity of the solar panel (Table VI). There has to be some other explanation for increase energy levels in the diffracted beam. One possibility is that diffraction breaks white light into 7 colours, simultaneously releasing the 'binding' energy

Another possibility is that areas covered by the direct and diffracted beams are different. The latter being higher will stimulate higher number of PV cells. If this were the plausible explanation, the ratio of currents induced by direct and diffracted beams should be the same irrespective of the intensities of the former. However, this does not appear to be the case. The ratio of the power (wattage) generated by the beams from the brightest central zone is $10.36(54.6 \mathrm{~mW} / 5.27 \mathrm{~mW})$ against $2.42(4.54 \mathrm{~mW} / 1.87 \mathrm{~mW})$ observed in the beams from the dimmer middle zone (Table III).

In experiments with the small solar panel, the size of the directly focused beam was adjusted to cover the entire panel without leaving any unstimulated PV cells. Even under such setting diffracted beams had higher energy levels as measured by induced current (Table VII). Since the direct beam had covered the entire panel, this is perhaps the most direct and strongest evidence that diffraction of white light beams is associated with release of extra energy, plausibly the 'binding' energy. The same phenomenon is observed in studies where four lasers are used to illuminated the entire solar panel (Table II)

Certain forms of inelastic scattering, such as Raman Scattering, are associated with release of energy [3]. However, it is restricted to a small fraction of scattered photons, approximately 1 in 10 million, and associated with changes in the frequency of the scattered photons, usually lower than the incident photons. Solely, on the quantitative basis our results, both on the lasers and the white light, cannot be attributed to Raman Scattering. Further, in studies on lasers, there is no change in the frequency of the photons as disrupted laser beam continues to be red monochromatic like the parent laser.

When blackbody is heated beyond certain temperature it starts emitting visible light in a sequential manner commensurate with temperature. It begins with red glow which appears around $600^{\circ} \mathrm{K}$, followed by other colours, yellow, green, and ending in bluish white waves at the temperature of more than $5000^{\circ} \mathrm{K}$. Max Planck interpreted the changes in the colour spectrum in terms of energy level and postulated that the energy is dispensed in 'quanta', an observation that laid the foundation 
for modern (quantum) physics [1]. The relationship between the frequency of a wave and the energy is governed by Einstein Planck equation $\mathrm{E}=h f$ where $h$ is the Planck constant and $f(c / v)$ the frequency of emitted light [4]. Thus, in the blackbody radiation there is linking of energy to the peak levels of particular wave length (colour) in the visible light spectrum. Besides the three basic colours, the visible colour spectrum has a number of combination colours - orange, yellow, indigo, brown, violet etc. Sun's radiations approximate the blackbody spectrum. White light, which is the dominant colour in sunlight, is generated around temperature of $5000^{\circ} \mathrm{K}$. Like in the Sun, the white light is generated at very high temperatures in a number of situation (blackbody radiation, incandescent blubs etc.). Thus, high energy is required to bring together waves of 7 colours that form the white light. Further, these colours are firmly bound together in their long journey from the Sun to Earth. This study suggests existence of 'binding' energy. That the 'binding' energy can be released by simple procedures like diffraction provides a new lead for improving harnessing of solar energy

Visible light spectrum stretches from wave length $380 \mathrm{~nm}$ to $750 \mathrm{~nm}$, a difference of $370 \mathrm{~nm}$ between the two extreme waves. The difference between two adjacent waves at the violet end is $0.26 \%$ ( 380 $\& 381 \mathrm{~nm})$ and that between waves in the red zone $0.13 \%(749$ and $750 \mathrm{~nm})$. Also, the red wave is about two times the violet wave. Since photons and waves represent two faces of the same coin, it is reasonable to assume that their size would be the same. One implication of this assumption is that the size of the photons of the waves mentioned above will likewise vary. Photons are massless at rest. But they are always in motion at the speed of light and therefore have relativistic mass. An imaginary bundle of white light containing one wave each in the visible spectrum will be a conglomeration of 370 waves of varying length and relativistic mass. Its two-dimensional structure would look like a trapezius with red and violet being its two parallel sides. But the red wave is almost double in size and relativistic mass of the violet wave. These differences would create an unstable structure and the waves would fall apart, especial if they are loose and travelling at the speed of light. However, nothing of that sort happens. Instead, the asymmetrical combination of 7 colours travels million miles at the highest known speed (speed of light) from the Sun to the Earth every moment as white light, defying natural disruptive forces. Obviously, the waves must have been kept together by some sort of a binding force. This contention is supported by the observations of this study.

It is difficult to predict the nature of the 'binding' force (energy). However, the author has calculated its strength in two steps. (a) The de Broglie equation $(p=h / \lambda)$ was used to get momentum and relativistic mass of the adjoining photons. (b) The force of attraction, which would be the binding force, was then calculated using Newton law of universal gravitation $\left(F=\mathrm{G} \mathrm{m}_{l} \mathrm{~m}_{2} / \mathrm{d}^{2}\right)$. The distance 
(d) was taken as the mean of the wave lengths of two adjoining waves (photons). The calculations are shown below: The author recognizes limitations of this very simplistic approach and that there could be other approaches.

Step 1: The relativistic mass was determined using de Broglie equation

$$
\begin{aligned}
& p=h / \lambda \\
& p=m \nu=m c=h / \lambda \\
& m=h / \lambda c
\end{aligned}
$$$$
\text { where } p \text { is the momentum of a photon, } h \text { Plank constant }\left(6.626 \times 10^{-34}\right) \text { and } \lambda
$$$$
\text { wave length. For calculation purposes the median wave length (556nm) and one }
$$$$
\text { higher (557nm) of the white light were used. }
$$$$
m=h / \lambda \mathrm{c}
$$$$
=6.626 \times 10^{-34} / 5.56 \times 10^{-7} \times 3.0 \times 10^{8}
$$$$
=0.397 \times 10^{-35}
$$$$
=3.97 \times 10^{-36} \mathrm{~kg} \text { for } \lambda 556 \text { and }=3.96 \times 10^{-36} \mathrm{~kg} \text { for } \lambda 557
$$

Step 2: Newton's law of universal gravitation was used to calculate force of attraction (the 'binding' energy) between the two photons.

$$
F=G \frac{m_{1} m_{2}}{d^{2}}
$$

Where $\mathrm{G}$ is the gravitational constant $\left(6.673 \times 10^{-11} \mathrm{~N} \mathrm{~m}^{2} \mathrm{~kg}^{-2}\right), m_{1}$ and $m_{2}$ relativistic masses of the two adjoining photons in $\mathrm{kg}$ and $d$ center to center distance between adjoining photons which is equal to mean of the size of the photons (wave lengths in meter)

$$
\begin{aligned}
F & =6.673 \times 10^{-11} \mathrm{~N} \mathrm{~m}^{2} \mathrm{~kg}^{-2} \times 3.97 \times 10^{-36} \times 3.96 \times 10^{-36} / 5.56510^{-7} \times 5.565 \times 10^{-7} \\
& =3.3874 \times 10^{-69} \mathrm{~N}
\end{aligned}
$$

Since there would be 370 (750-380) waves in the imaginary bundle of white light total force of attraction (binding force) would be

$$
\begin{aligned}
& =3.3874 \times 10^{-69} \mathrm{~N} \times 370 \\
& =1253.338 \times 10^{-69} \mathrm{~N}
\end{aligned}
$$


Likewise, for the two adjacent waves in the imaginary bundle in red laser $(\lambda 650 \pm 10$ nm) used in his study the 'binding' force is

$=1.825 \times 10^{-69}$

for the bundle of 20 waves $(650 \pm 10 \mathrm{~nm})$

$F=3.65 \times 10^{-68}$

Considering that each wave is coherent and bound on either side with wave of the same characteristics each imaginary red laser bundle would have double 'binding energy

$F=7.3 \times 10^{-68} \mathrm{~N}$

The concept of the' binding' energy trapped in sunrays also has direct relevance to harnessing of solar energy. The best photo-conversion efficiency of silicon solar cell, the most dominant photovoltaic (PV) cells used in solar panels, is claimed to be around 26\% [5]. Global attempts are being made to improve efficiency of solar panel. Progress in approaches used to improve efficiency of the PV cells are summed up from time to time by National Renewable Energy Laboratory (NREL), USA which has also brought out a monogram on concentrator photovoltaic technology [6,7] Most efforts to improve tapping of solar energy are so far directed towards improving performance of the PV cells. This study suggests yet another plausible approach of splitting the white rays making additional ('binding') energy available to the PV cells. This would be the first 'supply side' effort to improve efficiency of solar panels.

Nature uses its resources very efficiently, sometime with not so evident subtle 'hidden' logic. Radiation from the Sun, which can be equated with a furnace, are generated at the temperatures above $5000^{\circ} \mathrm{K}$. Although the sun radiations that reach the Earth cover the entire electro-magnetic spectrum, the dominant one is the infrared (heat) that accounts for $54 \%$ of the radiations. Visible light accounts for $45 \%$ and the rest $1 \%$ are the shorter wavelengths [8]. If the entire energy generated by the Sun were to be transmitted as infrared (heat waves) the Earth would have been scorched and uninhabitable. Dispensing the energy in two forms, light and heat, is obviously nature's mechanism to make the Earth inhabitable. Visible light is used in photosynthesis by plant chlorophyll making them the starting point for the human food chain. This study shows that additional energy (Latent light binding energy) is trapped in the visible sunlight that is generated at very high temperatures. 
Diffraction grating was discovered by James Gregory, the famous Scottish mathematician who used a feather of a white bird to split the Sunlight beam into spectrum of colours similar to that was obtained by Newton in his prism experiments [9]. Some species of migrating birds travel very long distances at high altitude where air temperature is much below the freezing point [10]. Alpine swifts, a bird species found in Southern Europe, can spend over six months flying without touching land [11]. Migratory birds show a number of physiological and metabolic adaptations [12]. Yet, there are gaps. This study shows that the splitting of white light is associated with release of extra ('binding') energy. In biology there is no structure without a function. Bird's feathers have several functions. It is tempting to suggest that splitting of white light (Sunlight) could be one of their additional functions to regulate the body temperature (birds are warm blooded animals) that could substantially reduce fuel (food) demand, a subtle way of reducing flying-weight, a distinct advantage during long flights. However, this hypothesis needs to be supported by more in-depth studies.

Lastly, whereas the classical (Newtonian) physics deals with macro objects, the quantum mechanics is all about the nature and behavior of matter and energy at the atomic and subatomic level [13]. Even 70 years after its dominance of the physics world, the latter is not without major controversies [14]. Binding energies have been described in physics mostly associated with atomic and sub atomic structures, which have definitive mass [15]. The chemical bond energies are between two atoms/molecules [16]. The present study suggests, for the first time, that massless energies may interact within themselves, a phenomenon even beyond the limits of quantum (modern) physics. However, much more research is needed to test the hypothesis.

\section{Material and Methods}

\section{Materials:}

Laser: Category IIIA Red $(650 \pm 10 \mathrm{~nm})$, Green $(532 \pm 10 \mathrm{~nm})$ and Blue $(405 \pm 10 \mathrm{~nm})$ laser pointers all of $<5 \mathrm{~mW}$ (made in China).

White light sources: White LED flashlight (Eveready DL40 Josh, 3.2 V; 150mA and 65 Lumen, Made in India); Bright sunlight between 11.00am and 1.00pm in summer months

Diffuser: A small strip $(3 \mathrm{~cm} \times 8 \mathrm{~cm} \times 0.3 \mathrm{~cm})$ of frosted window glass pane.

\section{Diffractors:}

For lasers: A glass microscope slide covered entirely on one side by a strip of a Surgical tape (3M Transpore) which had of 100 pores/100 sq. mm, each of $12-15 \mu \mathrm{m}$ diameter. 
For white flashlight and sunlight: Diffraction grating: Hilger Students grating 600L/mm; (HSG15K, Hilger Analytical, England)

\section{Solar cell panels:}

1. Monocrystalline photovoltaic silicon solar panel: Single panel $36 \mathrm{~mm} \times 30 \mathrm{~mm} \times 3 \mathrm{~mm} ; 4 \mathrm{~V}$, 30mA rating (KitsGuru KG420; Made in India)

2. Polycrystalline photovoltaic silicon panel: A locally manufactured $14 \mathrm{~cm} \mathrm{x} 8 \mathrm{~cm} \times 3 \mathrm{~mm}$ polycrystalline solar cell panel; 6 V $300 \mathrm{~mA}$ rating.

Digital Multimeter: Multimeter HTC EC1010-1; 1000V; Made in India.

Tachometer: Mextech DT-2234C Non-Contact Tachometer. Mextech Technologies India PVT. LTD

Fabricated aluminium rack: To study the possibility of the existence of the 'binding' energy both in flashlight and sunlight a medium size open rectangular aluminium rack with following features was fabricated (Fig.4).

1. The dimensions of the rack, which was made of $\mathrm{L}$ shaped aluminium rods, were $30 \mathrm{~cm} \mathrm{x}$ $21.5 \mathrm{~cm} \times 20.5 \mathrm{~cm}$.

2. It had four open $20 \times 20 \mathrm{~cm}$ shelves with a rectangular window of the size $14 \mathrm{~cm} \times 14 \mathrm{~cm}$.

3. The shelves were located at $28 \mathrm{~cm}, 25 \mathrm{~cm}, 22 \mathrm{~cm}$ and $8 \mathrm{~cm}$ from the base of the frame (Fig 4A).

4. A pane of thick cardboard of size $20 \mathrm{~cm} \times 20 \mathrm{~cm} \times 0.3 \mathrm{~cm}$ was placed on each shelf

5. The topmost cardboard shelf had four windows, each of $2.8 \mathrm{~cm}$ diameter, to accommodate 4 flashlights (Fig 1B).

6. The second shelf had four rectangular windows each of the size of $5.6 \mathrm{~cm} \times 3.7 \mathrm{~cm}$. A set of four diffraction grating (600 1/mm; Hilger) was fixed on these windows with Scotch-tape.

7. The third shelf was used to place the polychromatic solar panel.

8. The fourth shelf provided the strength to the rack and was also used to store ancillaries for experiments.

9. The flashlight, the grating and the solar panel were aligned in such a manner that the entire panel was lighted. Also, the beams passed through the centre of the grating when it was interposed between the flashlight and the panel.

10. To study solar energy, the same fabrication was used except that the flashlight was replaced by sunlight beams focused through one of the windows. As and when required the beam was 
diffracted by covering the window with a students grating (HSG15K, Hilger Analytical, England)

First shelf to accommodate the cardboard pane with four windows one each for one flashlight
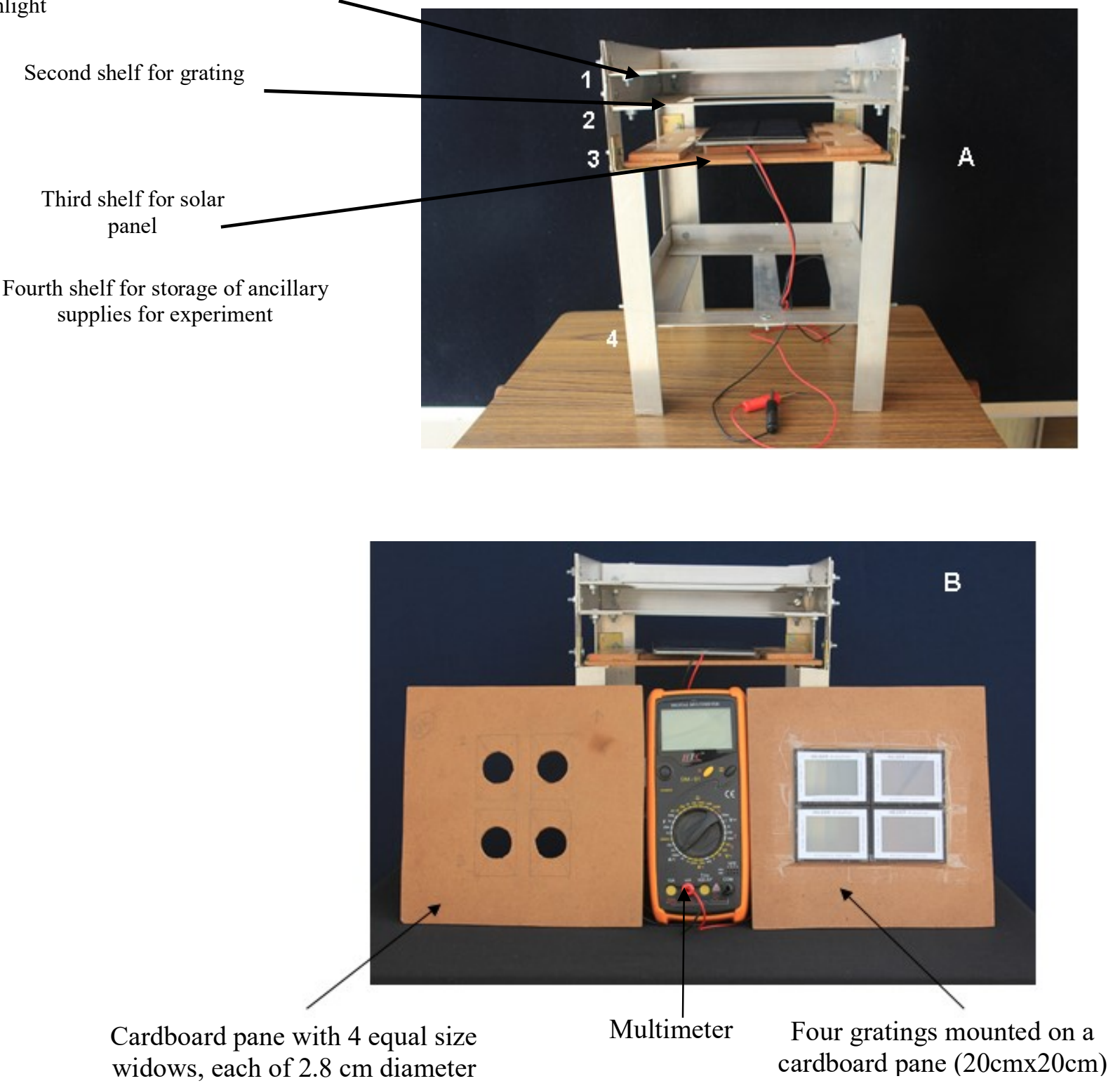

Cardboard pane with 4 equal size widows, each of $2.8 \mathrm{~cm}$ diameter cardboard pane $(20 \mathrm{~cm} \times 20 \mathrm{~cm})$

Fig 4: Fabricated aluminium rack (A) and the ancillaries (B) 


\section{Methods:}

\section{Lasers:}

The laser beam of each colour (Red, Green and Blue) was individually focused on the monocrystalline photovoltaic silicon solar panel (KitsGuru KG420; Made in India) attached to the Digital Multimeter. It had only one panel with the photovoltaic cells joined in series. Except for a small window of $18 \mathrm{~mm}$ diameter, the panel was covered with a thick black paper, which completely blocked photons from reaching the photovoltaic solar cells. The laser was kept at a distance of $40 \mathrm{~cm}$ from the panel and the diffuser/diffractor at 2.00 to $2.5 \mathrm{~cm}$ from the solar panel. In another study, bare solar panel was stimulated with four red lasers, each illuminating one quadrant (Fig. 1). To reduce the environmental photon background, all laser experiments were conducted in the night when the background was almost nil. Laser protective glasses were always used.

\section{White light and study design:}

Two sources of white light were used (a) white LED flashlight Eveready Josh DL 40; Made in India and (b) Sunlight. The flashlight worked on 3 AA dry batteries (4.5V). The polychromatic solar cell panelwas used in all studies on white light including the sunlight. To study the energy levels in beams of different light intensities, the flash light was placed in series with a variable rheostat and three input currents - 1.45A, 0.1A and 0.04A - were provided at constant voltage of 4.5V (Fig.5). The flashlight exhibited three progressively diminishing intensity zones from the brightest innermost to the dimmest outermost zones. To ensure uniformity in the size, essential for comparative studies, beams from each zone were individually passed through an aperture of $1 \mathrm{~cm}$ diameter (area $0.785 \mathrm{sq}$. $\mathrm{cm}$ ) made in a black screen, which otherwise blocked all other rays.

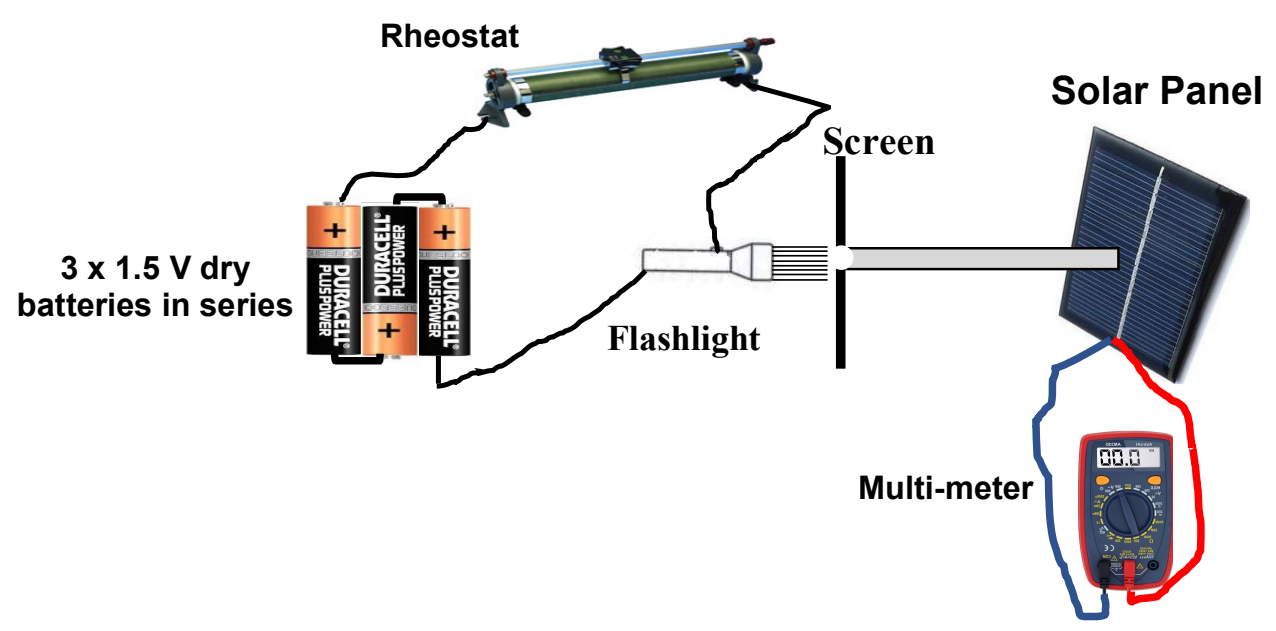

Fig 5. Circuit diagram 
Measuring energy levels in flashlight. So far, studies were lab based conducted in the night when the environmental photon background was almost nil. To test the applicability of these observations to the overall issue of solar energy, studies were conducted first in sunshade and later in broad daylight. The solar panel was exposed simultaneously to 4 LED white flashlights in sunshade using the fabricated aluminium rack (Fig 6). The flashlights were fixed to the cardboard pane with 4 windows and placed on the topmost shelve of the rack. The solar panel was kept on the third shelf. The flashlights were aligned such that each illuminated one quadrant, thus illuminating the entire solar panel (Fig. 6). The cardboard pane carrying the diffraction gratings was placed in the second shelf interposed between the flashlights and the solar panel as and when required. Energy levels were measured before and after diffraction of the beams.
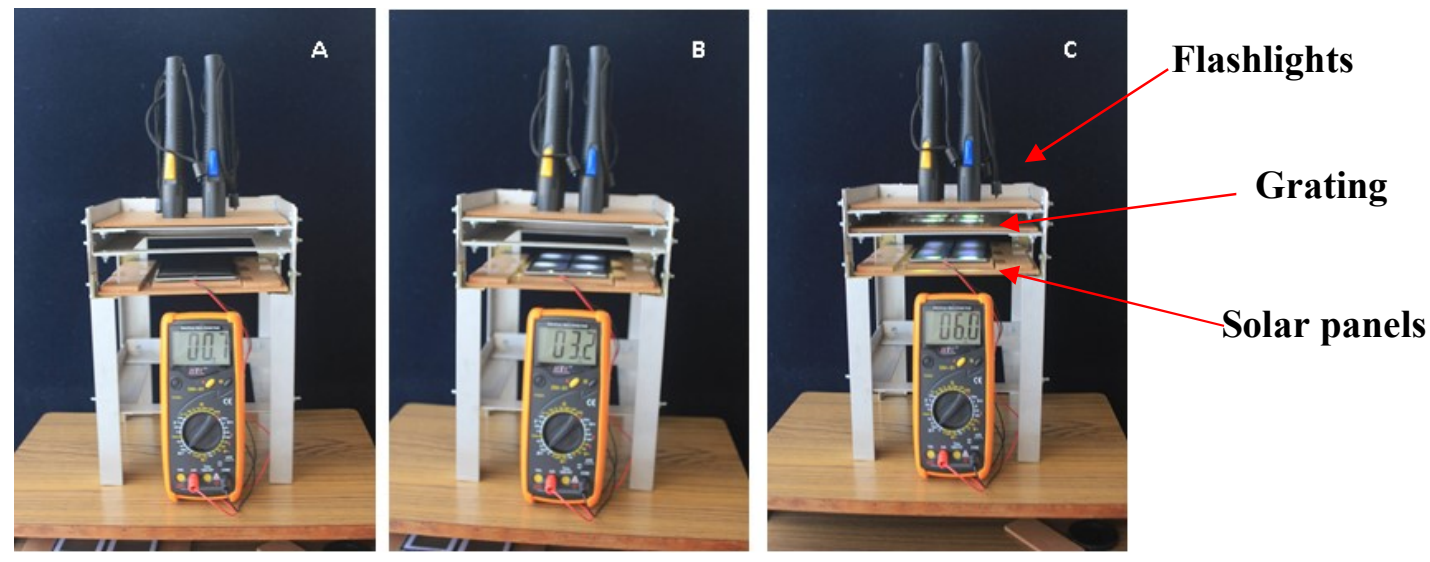

Fig 6. Four white LED flashlights were fixed to the cardboard pane with four windows each with diameter of $2.8 \mathrm{~cm}$ kept in the upper most shelf. The solar panel was kept in the third shelf. The cardboard carrying 4 diffraction grating $(600$ line $/ \mathrm{mm})$ was interposed between the flashlights and the solar panel. Reading were taken (A) without activating the flashlights and without the diffraction grating; (B) conditions same as A except that the flash lights were activated and (C) After activation of the flashlight four diffraction grating were interposed between the flashlights and the solar panel.

\section{Experiments with sunlight:}

The next set of experiments were carried out in broad sunlight. Energy levels were measured under three sets of experiments (Fig 6). (a) The solar panel was exposed directly to sunlight through the four windows and the open sides of the rack (direct beam; Fig 7A), (b) a beam of sunlight was additionally focused through one of the windows using a concave mirror $100 \mathrm{~mm}$ diameter and $f 150$ mm (focused beam; Fig. 7B) and (c) the focused beam was diffracted by passing it through the diffraction grating (diffracted beam; Fig.7C). Diffraction of focussed sunlight beam was associated with increase energy (current) levels. To study functionality of these alterations, a toy fan of $50 \mathrm{~mW}$ was placed in series with the solar panel and the multi-meter. The rotation per minute (RPM) of the 
fan was recorded using the tachometer under the three sets of conditions. Video recording was also done.
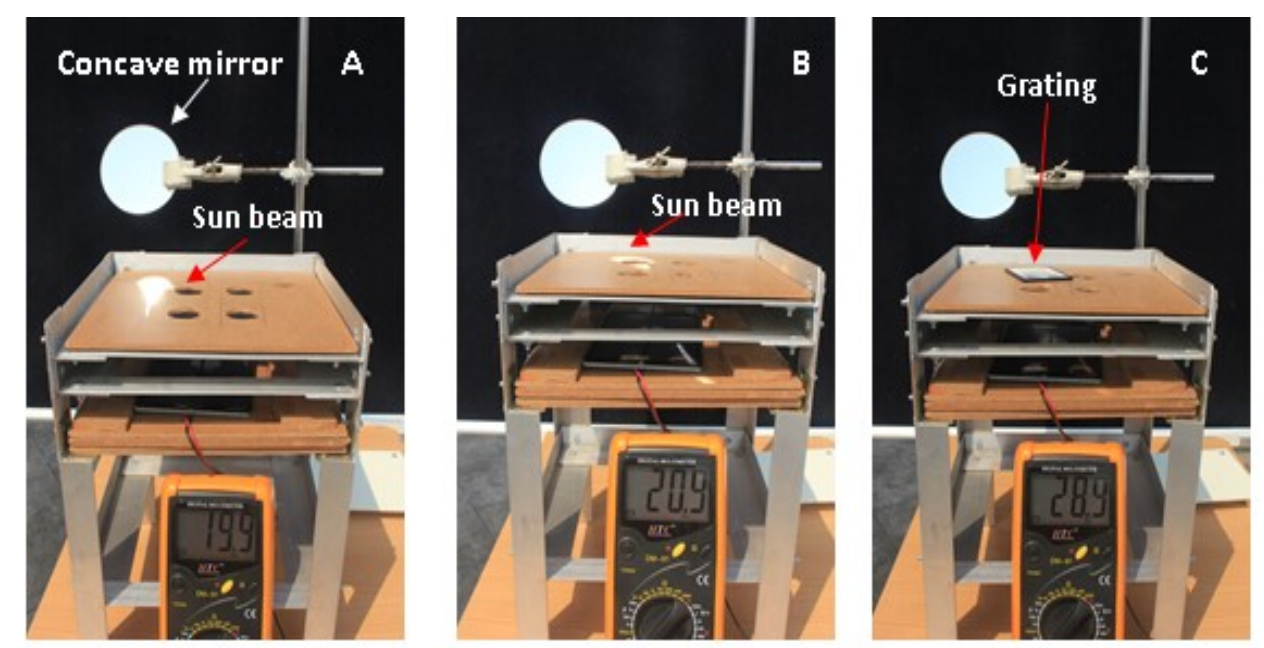

Fig 7: Design of experiments with sunlight (a) Solar panel in broad sunlight with focussed beam just outside a window (b) focused sunbeam on the panel through one of the windows and (c) the same as (b) but with interposed diffraction grating

Measurement of energy levels: Photon energy was measured in terms of Current (A) and Voltage (V) generated by laser and white light beams before and after their disruption (diffusion/diffraction).

\section{Statistical treatment;}

Paired readings for each experiment were taken at one seating lasting for about 25-30 min. In view of minor regional variations observed in solar panels, each experiment was repeated six times and results expressed as mean \pm SD. Students' paired t test was applied and P values of $<0.05,<0.01$ and $<0.001$ were considered statistically significant $\left(^{*}\right)$, highly significant $(* *)$ and very highly significant $(* * *)$ respectively.

\section{Conclusions:}

In conclusion, results of this study suggest existence of 'Latent Light Binding Energy' which binds laser waves, probably both end-on and side-on and only side-on in 7 coloured waves of the white light. Although, the scattered laser beam looks physically like a beam of ordinary diffuse light, it continues to be monochromatic and coherent in the phase identical to the parent beam. However, the disrupted beam cannot be sharply focused and reconverted into laser, probably due to the loss of the 'binding' energy. The energy, both in the laser and white light, can be released by simple procedures such as scattering (diffusion) for lasers and diffraction through diffraction grating for white light 
including the sunlight. That white light is formed in the Sun at very high temperature $\left(5000^{0} \mathrm{~K}\right)$ suggests high energy requirement for bring together the waves of 7 colour. This study also supports the existence of entrapped 'binding' energy that keeps these waves together in their long journey of millions of miles from the Sun to the Earth. That the energy could be released by simple procedures like diffraction provides a new lead to improve harnessing solar energy, where, currently, the focus is mainly on improving efficiency of solar cells.

Acknowledgement: Laboratory work related to the topic was carried out by the author in his homebased private lab during his tenure as an Honorary Scientist of Indian National Science Academy. Help extended by Mr. Prakash Pawar, Project officer in the Moving Academy of Medicine and Biomedicine, Pune (India), in fabricating gadgets used in this study, is deeply appreciated.

Author Contribution: The idea of the project evolved during interactive discourses of the author, who was a Professor of Pathology at the All India Institute of Medical Sciences, New Delhi, India, with medical students on "Physics through the eyes of a biologist" held in a few medical colleges in India in the last one and half year. This is a single author paper. The project was conceptualized by the author who is entirely responsible for generation of all experimental data and writing of the manuscript. No special software has been used. The project is self-funded; there is no external funding.

Competing interests: I declare that I have no financial and non-financial competing interests.

\section{References:}

1. Young H. D, Freedman, R.A., Ford; A.F., Particles behaving as waves. In Book University physics with modern physics $13^{\text {th }}$ Ed., $6^{\text {th }}$ Impression, Pearson India Education Services Pvt. Ltd. (India) 2016, pp1286-1317 ISBN 978-81-317-9027-4

2. Deo, M.G, A Method to Harness the 'Latent 'binding' Energy' in Light Beams to Improve Efficiency of Solar Panels. The Patent Office Journal 2017, No. 47,44419

3. Singh, R., C. V. Raman and the Discovery of the Raman Effect.

Physics in Perspective 2002, 4,399-420

4. Singh. V., Einstein and the quantum Current Science. (2005), 89, 2101-2112,

5. Yoshikawa, K., Kawski, H., Yoshida, W., et al. Silicon heterojunction solar cell with interdigitated back contacts for a photoconversion efficiency over 26\%. Nature energy 2017 ,4, doi:10.1038/enenrgy.2017.32

6. National Renewable Energy Laboratory (NREL). Photovoltaic research- Efficiency chart https://www.nrel.gov/pv/ (accessed on July 28,2018)

7. Current Status of Concentrator Photovoltaic (Cpv) Technology. Fraunhofer ISE | NREL CPV Report 1.3 April 2017 TP-6A20-63916 3 | 27

https://www.ise.fraunhofer.de/content/dam/ise/de/documents/publications/studies/cpv-reportise-nrel.pdf (Accessed on July 27,2018)

8. Thermal Energy from Light - SERC - Carleton https://serc.carleton.edu/integrate/teaching materials/energy sustain/student materials/ther mal energy .html (Accessed on July 27,2018) 
9. Correspondence of Scientific Men of the Seventeenth Century. Ed. Stephen Jordan Rigaud; Letter from James Gregory to John Collins, dated 13 May 1673 (Oxford, England: Oxford University Press, 1841), vol. 2, pp 254 (https://books.google.bj/books?id=csZEAAAAcAAJ\&printsec $=$ frontcover\&hl=fr\#v=onepag e\&q=page \%20254\&f=false (Accessed July 29,2018)

10. The Basics of Bird Migration: How, Why, and Where $\mid$ All About Birds. The Cornell Lab of Ornithology. https://www.allaboutbirds.org/the-basics-how-why-and-where-of-birdmigration/ (Accessed on July 27,2018)

11. Liechti, F., Witvliet, W., Weber, F., Bachler. E., First evidence of a 200-day non-stop flight in a bird. Nature Comunications 4, doi:10.1038/ncomms 3554 (Accessed on July 27,2018)

12. Butler, P.J. The physiological basis of bird flight. Phil. Trans. R. Soc. B 2016, 371:20150384 (http;//dx.dou.org/10.1098/rstb.2015.0384. (Accessed on July 27,2018)

13. Haddad, D, Seifert, F, Chao L.S., et al. Bridging classical and quantum mechanics. Metrologia. 2016, 53, A83-A85,

14. Merali, Z. Quantum physics. What is really real?-A wave of experiments is probing the root of quantum weiderness. Nature 2015,521, 278-280.

15. Young H. D, Freedman, R.A., Ford; A.F., Nuclear binding and nuclear structure. University physics with modern physics $13^{\text {th }}$ Ed., $6^{\text {th }}$ Impression, Pearson India Education Services Pvt. Ltd. (India) 2016 pp1444-1447. ISBN 978-81-317-9027-4

16. Nave, R Chemical Bonds - HyperPhysics Concepts hyperphysics.phy-astr.gsu.edu/hbase/Chemical/bond.html (Accessed on July 27,2018)

Supplementary materials, data Deposit and Software Source Code: All data have been included in the MS. There are no additional supplementary data except the video. No special software has been used. Data would be made available to all readers.

Research and Publication Ethics: Ethical approval not required as research has no human or animal experimentation. All other publication ethics as stated in instruction to authors have been strictly followed. No figure or any other imported material has been used in the preparation of the MS. 